\title{
Reasons and Solutions for Female Employment Discrimination in the Background of the "Universal Two-Child Policy"
}

\author{
Qiwen Tang ${ }^{1, *}$ \\ ${ }^{1}$ Department of law and politics, North China electric power university. Baoding, Hebei 071000, China \\ *Corresponding author. Email:2097958485@qq.com
}

\begin{abstract}
The implementation of the "universal two-child policy" has intensified the conflict between women's work and family, and further aggravated occupational gender discrimination. This article summarizes and analyzes the reasons for female employment discrimination from four aspects, which are as follows, coexistence of insufficient legal protection and excessive protection, the lack of public services, increase in labor costs during female fertility period and the impact of traditional gender perspectives. For the above reasons, we propose some solutions from the government, employer, individual and family levels.
\end{abstract}

Keywords: the "universal two-child policy", female employment discrimination, reasons, solutions

\section{Introduction}

The fertility and rearing behaviors of women are of irreplaceable significance to the reproduction of humankind and social well-being. The introduction of the comprehensive two-child policy will have an impact on women's employment equality. This is an unavoidable fact. Due to the possibility of female employees taking two maternity leave and breastfeeding leave, coupled with women's need to take care of work and family, time and energy will be more dispersed, resulting in the hiring of employers to avoid the childbirth cost of the second child. Women's cards are set up for employees, and restrictions are placed on the set-up, training, and even promotion of pregnant female employees, which makes women's employment inequality, such as difficulty in finding jobs, poor development, and low treatment, significantly more serious.

In the context of the new fertility policy, how do women balance fertility and employment? How to weaken employment discrimination and create an inclusive employment environment? It has become an urgent issue of people's livelihood and society. This article also has important theoretical and practical significance.

\section{Reasons for Female Employment Discrimination in the Background of the "universal two-child policy"}

\subsection{Coexistence of insufficient legal protection and excessive protection}

The survey found that insufficient legal protection is the primary factor affecting women's unequal employment. China's existing anti-employment discrimination clauses are scattered in the Constitution and the Law on the Protection of Women's Rights and Interests, but no special antidiscrimination law has been issued. Separate laws such as the "Labor Law" also only make some principled provisions. They neither clearly define the constituent elements of employment sex discrimination, nor specify the specific responsibility bearers and punishment provisions, thus leading to anti-employment discrimination. The lack of implementation mechanism and the absence of enforcement agencies, policy makers and executors have disputes on employment discrimination and government supervision, and implicit gender discrimination against some employers. Because laborers have difficulty obtaining evidence, they have not been clearly resolved. Method.

In addition, our country still exists in the legislation "the over-protection causes the weakening and the segregation" to the female ${ }^{[1]}$.In addition to the "procreation period", the legal protection for women includes the "lactation period", "menopause" and "menstrual period". Protection leads to an increase in employment costs for enterprises, which makes them think that "women are a burden to employers", and will naturally discriminate against women in employment. 
Although many laws and regulations promulgated in China include women's employment, maternity, labor protection and other aspects, they lack operability, and the responsibilities and details of various parties have not been made in detail. Therefore, China should promulgate the "Anti-Employment Discrimination Law" as soon as possible to define the definition, standards, and classification of employment discrimination, the responsibilities of illegal employers, the responsibilities of supervisory departments, and the intensity of punishment to improve the legal basis for equal employment of women. In addition to having a sound law, we must also strictly enforce the law. China can learn from the practices of Sweden, the United States and other countries, set up special antiemployment discrimination agencies or rights protection agencies, accept and handle women's appeals, petitions, mediation and arbitration, and represent women in litigation in courts. After the relevant departments file a case, they must strictly enforce the law and increase the punishment for infringing on women's equal employment.

Aiming at the difficulty of obtaining evidence of "invisible discrimination", it is suggested to solve it through the method of reverse proof. As long as the employee raises the employment unit's suspected sex discrimination in employment, the proof work will be carried out by the employer. They need to prove that they do not have sex discrimination and explain the reasons for not accepting. Units will be punished accordingly

\subsubsection{Improve the maternity security system to reduce the burden on employers}

In order to reduce the loss caused by the female leaving the company during childbirth, the government is suggested to improve the maternity security system. Should increase to did not participate in maternity insurance unit punishment, urge its participation as soon as possible; Strengthen labor protection during pregnancy and lactation, and provide active job rotation for professional women in special periods At the same time, the government should also increase the financial support to safeguard. The social insurance expenses paid by the employer and the wages and allowances borne by the employer during maternity leave of female employees may be appropriately subsidized by the government. At the same time, the government can reduce the burden on employers by giving tax breaks to those employers that employ a certain number of women and provide flexible jobs for women after childbirth.

\section{SOLUTIONS FOR FEMALE EMPLOYMENT DISCRIMINATION IN THE BACKGROUND OF THE "UNIVERSAL TWO-CHILD POLICY"}

\subsection{Government level}

\author{
3.1.1. Improve the legal system and strengthen \\ labor market supervision
}

\subsubsection{Develop public services to reduce the burden of breastfeeding women}

Taking care of infants and young children is a major factor that makes it difficult for women to balance family and work. In order to effectively implement the "two-child policy", the government should actively guide all units to provide social support for professional women. The Chinese government 
must vigorously develop public service undertakings, clarify the work of relevant supervision departments as soon as possible, and strengthen the supervision and management of public utilities; increase financial support for public childcare services and strengthen the training of childcare teachers; The establishment and charging standards of the institution are clearly stipulated, and the management and supervision of institutions such as babysitters are strengthened; private kindergartens are encouraged, and childcare institutions are established next to large communities and qualified employers to alleviate the pressure on women at birth.

\subsubsection{Reasonably regulate the employment autonomy of employers}

The employment autonomy of enterprises ${ }^{[2]}$ began in the 1980s. Enterprises have the right to determine the number of workers and conditions of their own work in accordance with national regulations and according to their own needs. It is true that enterprises enjoy autonomy, but their power is irresponsible. Some companies rely on their autonomy to evade the employment of female employees, which is obviously an abuse of power. To reduce female employment discrimination caused by the "two-child", the state must reasonably regulate the autonomy of employment, and must not excessively allow companies to borrow free labor to discriminate against employers in terms of gender selection.

\subsection{Employer level}

\subsubsection{Change perceptions of women and create a good corporate atmosphere for gender equality}

In the traditional society, the responsibility orientation of women mostly stays at the family level of "taking care of husband and children". In today's society, in order to change women's unequal employment situation, it is necessary to break this traditional thinking, and enterprises should take the initiative to create a gender equal workplace atmosphere. First of all, the enterprise should formulate the enterprise development plan of gender equality, give male and female employees the same opportunity for entry and promotion. Secondly, we should establish the corporate culture of equality between men and women and eliminate the discrimination against women. At the same time, the enterprise should treat the women who have a birth and a second birth equally, give them spiritual care, relieve their stress and anxiety about work and family during the reproductive period.

\subsubsection{Conditional employers implement flexible working system for women}

The busyness of taking care of infants and children after childbirth makes women's avatars lack skills, and the contradiction between family and work is prominent, which has become a major factor restricting women's career development. With the development of technology, the Internet has made it possible to implement flexible employment methods. The flexible working system is a system that replaces fixed locations and fixed hours to perform unified work. Its employees can choose the time and place for subsequent work after completing prescribed tasks or durations. Qualified enterprises can let women carry out remote work and work from home according to the actual situation of women. In addition, enterprises implement flexible working systems in a variety of ways. Not only can women's work places and working hours be flexibly managed, their working methods can also be adjusted according to actual conditions. This can effectively save the company's office costs and women's time costs to and from work, and effectively alleviate women's conflicts at home and work.

\subsection{Personal and family level}

\subsubsection{Break through traditional concepts and straighten your status}

Affected by traditional concepts, many times like others, women also have wrong understanding and positioning of themselves. When conflicts arise between work and family, they tend to sacrifice their work as a solution. For example, reducing your working time, reducing your productivity, or even being pessimistic about your career and relaxing your job requirements. In fact, such a narrow thinking is incorrect. Only by correcting their work attitude can women give themselves the motivation to improve their self-work skills, and then enhance their competitiveness in the job.

\subsubsection{Clear career plan and expand knowledge reserve}

Most women experience career interruptions because of childbearing or childcare. The reduction of human resources caused by occupational interruptions will lead to insufficient employment capital for women when they return to the workplace, which in turn will reduce the scope of employment. Therefore, women should have an in-depth understanding of their moral and technical expertise before giving birth, pinpoint their career positioning, make a reasonable career plan, and prepare for their return to the workplace after giving birth. At the same time, women 
two-child" policy, this disadvantage may be strengthened. Based on the analysis above, it is not difficult to see that the reasons for this situation are various, including lack of government legislation, inadequate social security, indiscriminate pursuit of interests by enterprises, and social concepts. Therefore, this article proposes corresponding solutions for each subject in the society, hoping that the whole society can work together. However, the analysis in this article is still not comprehensive, and there may be deeper cruxes in women's employment discrimination. Therefore, we also call on the society to pay more attention to this aspect and conduct in-depth research on employment discrimination in order to completely solve this problem.

\section{REFERENCES}

[1] Guo huimin, ding ning, "legislative model selection of gender equality in employment", journal of China youth university for political science, 3rd issue, 2006.

[2] Article 31 of the Law on Industrial Enterprises of the Whole Nation states," Enterprises have the right to hire and fire employees in accordance with the rules of the court and the State Council."

[3] People's Daily. Two children, long maternity leave (livelihood survey comprehensive two-child new security) [EB/OL] http://www.paper. People. com.cn/RMRB/HTML/201705/04/nw.d110000renmrb_20170504_1-13.htm(201705-30) [2018-06-30] 